\title{
Peran Pelatih dalam Pembinaan Prestasi Atlet pada Organisasi Taekwondo Profesional
}

\author{
Tifani Faradita Muslima1 E Fathul Himam $^{2}$ \\ Fakultas Psikologi Universitas Gadjah Mada
}

\begin{abstract}
This research was conducted with the aim of seeking a more in-depth understanding of the training strategies carried out by trainers on professional taekwondo athletes in building athletic achievements. Research uses a qualitative approach with phenomenological methods to capture phenomena that occur in a problem. The analysis is used through the epoche process, horizonalization with the process of reducing phenomenology, imaginative variation, and taking the synthesis of the meaning and essence of the phenomenon under study. The credibility of the results of the study was carried out using the triangulation method and member checking. The results of the study indicate that the strategy of coaching carried out by the trainer is to build support through communication, brotherhood and organizational support; learning through learning from experience and self-development; and coaching through mental coaching, achieving achievement, and sensitivity to athletes.
\end{abstract}

Keywords: pembinaan prestasi olahraga; pelatih, atlet; taekwondo profesional

Abstrak. Penelitian ini dilakukan dengan tujuan mencari pemahaman yang lebih mendalam terkait strategi pelatihan yang dilakukan oleh pelatih terhadap atlet taekwondo profesional dalam membangun prestasi atlet. Penelitian menggunakan pendekatan kualitatif dengan metode fenomenologi untuk menangkap fenomena yang terjadi di dalam sebuah permasalahan. Analisis yang digunakan melalui proses epoche, horizonalization dengan proses reduksi fenomenologi, variasi imajinatif, serta mengambil sintesa makna dan esensi dari fenomena yang diteliti. Kredibilitas hasil penelitian dilakukan dengan menggunakan metode triangulasi dan member checking. Hasil penelitian menunjukkan bahwa strategi pembinaan yang dilakukan oleh pelatih adalah membangun dukungan melalui komunikasi, persaudaraan, dan dukungan organisasi; pembelajaran melalui belajar dari pengalaman dan pengembangan diri; serta kepelatihan melalui pembinaan mental, langkah mencapai prestasi, dan kepekaan terhadap atlet.

Kata Kumci: pembinaan prestasi olahraga; pelatih, atlet; taekwondo profesional

\footnotetext{
${ }^{1}$ Korespondensi mengenai artikel ini dapat dilakukan melalui email tifani.fara@gmail.com

${ }^{2}$ Atau melalui: fathulimam@ugm.ac.id
} 
Kekuatan sebuah negara tidak lagi hanya dilihat dari kesejahteraan, pendidikan, ekonomi, dan kekuatan militer, namun juga dalam bentuk olahraga. Undang-Undang Republik Indonesia (UU RI) Nomor 3 tahun 2005 alinea 3 tentang Sistem Keolahragaan Nasional (SKN) menimbang bahwa mencerdaskan kehidupan bangsa melalui instrumen pembangunan nasional di bidang keolahragaan merupakan upaya meningkatkan kualitas hidup manusia Indonesia secara jasmaniah, rohaniah, dan sosial dalam mewujudkan masyarakat yang maju, adil, makmur, sejahtera, dan demokratis berdasarkan Pancasila dan Undang-Undang Dasar Negara Republik Indonesia tahun 1945.

Pelaksanaan olahraga memiliki berbagai keuntungan. Penelitian yang dilakukan oleh Barton, Griffin, dan Pretty (2012) menyatakan bahwa ada pengaruh yang positif dari pelaksanaan olahraga terhadap kepercayaan diri dan suasana hati. Siswa yang juga seorang atlet memiliki regulasi diri yang lebih baik dalam membagi waktu antara kompetisi olahraga dan prestasi akademis (Jonker, Elferink-Gemser, \& Visscher, 2010). Selain itu, partisipasi di dalam olahraga mampu meningkatkan kemampuan akademis dan matematis siswa (Bradley, Keane, \& Crawford, 2013; Domazet, Tarp, Huang, Gejl, Andersen, Froberg, \& Bugge, 2016). Partisipasi di dalam olahraga juga secara positif mampu meningkatkan kualitas hubungan antara orangtua dengan anak berdasarkan pada aspek kepercayaan, komunikasi, dan alienation (Sukys, Lisinskiene, \& Tilindiene, 2015).

Olahraga juga mampu mempererat dan membina persatuan dan kesatuan bangsa, memperkukuh ketahanan nasional, dan mengangkat harkat, martabat, dan kehormatan bangsa seperti yang tercantum dalam UU SKN Bab II Pasal 4. Prestasi yang tinggi di bidang olahraga diharapkan dapat menjadi alat untuk mengukuhkan jati diri bangsa yang berdaulat serta mampu bersaing dengan bangsa lainnya. Olahraga prestasi yang bertujuan untuk mencapai prestasi menjadi penting kedudukannya karena olahraga ini tidak hanya membina kesehatan dan kebugaran masyarakat namun juga dapat mengembangkan dan membina olahragawan agar mampu berkompetisi untuk mengharumkan nama Indonesia di kancah internasional. Olahraga prestasi menjadi penting karena merupakan salah satu tolak ukur dari kegiatan olahraga yang ada di Indonesia.

Prestasi merupakan penguasaan terhadap bahan atau materi tertentu (Enre, 1979). Prestasi merupakan hasil kecakapan, kesuksesan, atau taraf kemampuan yang diperoleh seseorang setelah melakukan kegiatan belajar dan berlatih dengan sengaja menurut pendekatan perilaku. Prestasi di dalam olahraga memiliki pengertian yang lebih spesifik. Prestasi olahraga adalah aktualisasi dari akumulasi hasil proses latihan yang ditampilkan atlet sesuai dengan kemampuan yang dimilikinya. Prestasi olahraga merupakan hasil yang dicapai oleh atlet pada cabang olahraga tertentu (Setyobroto, 2002). Selain itu menurut Cashmore (2008), prestasi atlet dalam berkompetisi merupakan hasil dari serangkaian proses belajar dan latihan yang dilakukan sebelumnya.

Salah satu kontributor dari pencapaian prestasi atlet di Indonesia adalah cabang olahraga beladiri Taekwondo. Taekwondo adalah olahraga beladiri yang berakar pada beladiri tradisional Korea. Taekwondo berarti seni atau cara mendisiplinkan diri atau seni beladiri yang menggunakan teknik kaki 
dan tangan kosong (Suryadi, 2003). Tae dalam taekwondo berarti tendangan atau serangan menggunakan kaki, kwon berarti pukulan atau serangan menggunakan tangan, dan do berarti prinsip, seni, atau cara mendisiplinkan diri. Taekwondo dapat diartikan sebagai "the way of kicking and punching" (Pottle \& Pottle, 2013). Tiga materi terpenting dalam berlatih taekwondo adalah jurus dalam beladiri taekwondo (taegeuk), teknik pemecahan benda keras dalam taekwondo (kyukpa) dan pertarungan dalam beladiri taekwondo (kyoruki) (Suryadi, 2003).

Olahraga beladiri taekwondo mulai berkembang ke Indonesia pada tahun 1970-an, dimulai dari aliran Taekwondo yang berafiliasi ke ITF (International Taekwondo Federation) yang bermarkas besar di Toronto Kanada, serta aliran Taekwondo yang berafiliasi ke WTF (The World Taekwondo Federation) yang berpusat di Kukkiwon, Seoul, Korea Selatan. Atas kesepakatan bersama dan melihat prospek perkembangan di dunia olahraga nasional dan internasional, maka Musyawarah Nasional Taekwondo pada tanggal 28 Maret 1981 berhasil menyatukan kedua organisasi Taekwondo tersebut, menjadi organisasi baru yang disebut Taekwondo Indonesia (Taekwondo Indonesia, 2003) dan seiring dengan perkembangannya, muncul taekwondo profesional di Indonesia.

Penelitian ini berfokus kepada taekwondo profesional. Hal ini dikarenakan masih jarangnya penelitian yang membahas mengenai taekwondo profesional di Indonesia. Prestasi yang diraih oleh atlet yang tergabung dalam organisasi taekwondo profesional di Indonesia cenderung meningkat. Atlet taekwondo profesional yang berada di Daerah Istimewa Yogyakarta (DIY) juga telah berhasil menorehkan berbagai prestasi. Prestasi yang diraih oleh taekwondo profesional DIY merupakan prestasi nasional dengan keberhasilan atlet taekwondo profesional DIY menjuarai kejuaraan nasional sehingga scope penelitian ini merupakan nasional.

Keberhasilan atlet taekwondo profesional dalam meraih prestasi merupakan kontribusi dari berbagai macam faktor. Pencapaian prestasi olahraga merupakan hasil kerja yang membutuhkan kesiapan dari segala bidang seperti kesiapan program latihan (perencanaan), kesiapan sarana dan prasarana, kesiapan pelatih untuk melatih, kesiapan atlet untuk melaksanakan program pelatihan, dan tersedianya dukungan dari lingkungan. Bentuk dukungan yang membantu dalam pencapaian prestasi yaitu karakteristik fisiologi atlet, gizi makanan yang dikonsumsi oleh atlet, lingkungan keluarga, lingkungan tempat latihan, serta lingkungan sekolah (Bompa, 2000).

Strategi didefinisikan sebagai rencana yang cermat mengenai kegiatan untuk mencapai sasaran khusus, sedangkan pembinaan didefinisikan sebagai usaha, tindakan, dan kegiatan yang dilakukan secara efisien dan efektif untuk memperoleh hasil yang lebih baik (Departemen Pendidikan Nasional, 2008). Pembinaan adalah aktivitas atletik yang sistematis pada durasi yang lama, meningkat secara progresif dan individual, dan bertujuan untuk membentuk fungsi fisiologis dan psikologis agar mampu mencapai tugas yang dibebankan (Bompa, 1994). Berdasarkan definisi tersebut, maka pembinaan prestasi adalah tindakan yang dilakukan secara efisien, efektif, dan berkelanjutan untuk mencapai hasil yang lebih baik yaitu prestasi atlet pada tingkat nasional dan internasional. 
Faktor-faktor yang mempengaruhi hasil latihan para atlet adalah faktor endogen dan faktor eksogen (Sajoto, 1990). Selain itu, menurut Matveyev (1981) faktor dan kondisi yang secara langsung dan tidak langsung berpengaruh terhadap dinamika pencapaian prestasi olahraga adalah sebagai (1) bakat alamiah individu atlet dan derajat persiapan mereka untuk meraih kemenangan, (2) efektivitas sistem pelatihan yang meliputi konten pelatihan, organisasi, serta ketersediaan sarana material dan teknikal, dan (3) lingkup gerakan olahraga dan kondisi sosial secara general terhadap perkembangan dunia olahraga.

Pelatih memiliki dampak yang sangat besar terhadap prestasi atlet taekwondo profesional. Pelatih yang membina proses pelatihan atlet memiliki pengaruh kritis yang membantu atlet untuk berlatih secara sungguh-sungguh (Jarvis, 1999). Penelitian yang dilakukan oleh Harrell (2013) menunjukkan bahwa peran instruktur atau pelatih sangat penting dalam pelatihan taekwondo. Pelatih dapat memberikan pengaruh kuat terhadap perilaku dan sifat murid yang diampunya. Menurut Departemen Pendidikan Nasional (2008), pelatih adalah orang yang melatih suatu bidang tertentu dalam hal ini olahraga. Pelatih merupakan sebuah profesi melalui sebuah pendidikan formal yang diselenggarakan oleh lembaga pendidikan tinggi maupun induk organisasi cabang olahraga yang bersangkutan. Berdasarkan pada perspektif pembelajaran sosial, pelatih harus mampu memberikan teladan dan memberikan dukungan positif untuk perilaku yang tepat dan penguatan secara negatif untuk perilaku yang tidak pantas. Hal lain yang tidak kalah penting adalah kemampuan pelatih untuk membangun hubungan yang baik dengan para atlet (Jowett \& Poczwardowski, 2007).

Penelitian lain yang dilakukan oleh Gwozdecky (2006) menunjukkan bahwa pelatih yang menggunakan taktik yang berorientasi untuk menang pada kejuaraan memiliki tim dan atlet yang lebih sukses dibandingkan dengan mereka yang tidak melakukan taktik tersebut. Pengambilan keputusan yang kompetitif yang dilakukan oleh pelatih juga mempengaruhi pengembangan permainan atlet. Pelatih harus melihat dari sisi proses pelatihan dan hasil yang ingin dicapai secara bersama-sama untuk mendapatkan hasil yang maksimal (Naylor, 2006). Pelatih yang secara aktif mencari informasi mengenai pengetahuan olahraga juga memiliki kemampuan yang lebih baik dibandingkan dengan pelatih yang cenderung pasif (Reade, Rodgers, \& Spriggs, 2008). Penelitian yang dilakukan oleh North (2007) menunjukkan bahwa tipe kepemimpinan yang ditunjukkan oleh pelatih merupakan determinan mayor terhadap kualitas partisipasi olahraga. Pelatih dapat memberikan dampak yang positif dan negatif dalam kehidupan atlet pada semua level kompetisi. Hubungan yang terjalin secara baik antara pelatih dengan atlet dapat meningkatkan prestasi.

Penelitian yang dilakukan oleh Chrila dan Chrila (2015) menyatakan bahwa performansi atlet dapat ditingkatkan melalui manajemen performansi yang didukung oleh pelatih. Pelatih yang memiliki pengalaman dan kapabilitas yang sesuai akan berdampak pada peningkatan kesiapan dan profesionalisme dalam pelatihan atlet. Pelatih yang mendapatkan pelatihan transformational leadership juga 
memberikan pengaruh terhadap pengalaman dan pengetahuan kognitif serta peningkatan dalam pencapaian goal setting atlet (Vella, Oades, \& Crowe, 2013). Pelatihan atlet yang tepat juga mampu meningkatkan performansi atlet (Chuan, Yusof, \& Shah, 2013), yang pada akhirnya berpengaruh terhadap prestasi atlet. Selain itu, atlet yang dibimbing oleh pelatih yang mendapatkan pelatihan dalam program olahraga memiliki kemampuan personal dan sosial yang lebih baik dibandingkan dengan atlet yang dibimbing oleh pelatih yang tidak mendapatkan pelatihan (MacDonald, Cote, \& Deakin, 2010).

Secara tradisional, pelatih dan atlet berfokus pada usaha-usaha mereka di dalam melakukan pelatihan secara fisik. Berjalannya waktu, teknik, taktik, dan aspek psikologi menjadi peran yang sangat penting dan tidak dapat dipisahkan dalam pelatihan atlet. Psikologi dipandang sebagai salah satu faktor kunci dalam performansi puncak atlet dan kesejahteraan (wellbeing) atlet di dalam olahraga (Dosil, 2008). Oleh karena itu, pelatihan mental atlet menjadi hal yang sangat penting untuk dilakukan oleh setiap pelatih yang menangani atlet dalam olahraga prestasi. Pelatihan mental atlet yang dilakukan dapat meningkatkan atensi, mengontrol arousal, dan meningkatkan performansi di dalam olahraga (Howland, 2006). Kesuksesaan seorang pelatih terlihat dari proses dan hasil yang dicapainya. Berdasarkan rangkuman dari keempat responden, sukses yang menjadi tolak ukur mereka adalah mampu mempertahankan klub, memiliki anggota yang terdiri dari anggota regular dan anggota atlet, pelatih dan atlet secara konsisten tetap berlatih dan bertahan untuk menekuni olahraga taekwondo, atlet lancar dalam menempuh pendidikan dan tercapai citacitanya untuk pendidikan yang lebih tinggi, serta atlet mendapatkan juara pada kejuaraan nasional dan internasional.

Faktor organisasi dan pelatih keduanya memegang peranan sangat penting bagi perkembangan prestasi atlet taekwondo profesional. Meskipun demikian, ada perbedaan mendasar di dalam proses pembinaan atletnya yang keduanya saling berkaitan dan melengkapi satu sama lain. Berdasarkan wawancara awal dengan Sekretaris Jenderal organisasi taekwondo profesional DIY, terungkap bahwa organisasi taekwondo profesional lebih mengurusi masalah teknis seperti Ujian Kenaikan Tingkat (UKT) setiap 3 bulan sekali, ujian DAN bagi pemegang sabuk merah strip dua dan sabuk hitam, dan sebagai penyelenggara kejuaraan baik daerah, nasional, maupun internasional. Hal ini diperlukan agar proses pembinaan yang dilakukan dapat terarah dan sesuai target yaitu visi dan misi organisasi, sedangkan peran pelatih melakukan pembinaan secara langsung bagi atlet yang dibimbingnya serta menyusun program pelatihan yang tepat bagi atletnya. Hal ini dikarenakan organisasi taekwondo profesional Pusat tidak mengurusi masalah program pembinaan dan hal tersebut diserahkan sepenuhnya terhadap pelatih. Setiap pelatih memiliki strategi yang berbedabeda untuk mengembangkan atletnya.

Pelaksanaan pemberian kuasa pelatihan kepada pelatih dilakukan karena pelatih yang paling mengetahui mengenai kondisi atletnya masingmasing. Hal ini sejalan dengan Bompa (1994) yang menyatakan bahwa hal yang penting dari sebuah pengembangan sistem pembinaan adalah pembentukan 
model pembinaan baik pada pendekatan jangka pendek atau jangka panjang. Model ini kemudian dilakukan oleh semua pelatih namun setiap pelatih memiliki tempatnya sendiri dan berdasarkan pada kemampuannya masing-masing dapat memperkaya sistem yang telah dibuat tersebut. Lebih lanjut, pelatih melalui kemampuan dan ketrampilannya harus menerapkan sistem spesifik berdasarkan klubnya, lingkungan sosial dan alamiah, serta karakteristik masing-masing atlet.

Organisasi taekwondo profesional sering menyelenggarakan pertandingan kejuaraan bagi atlet internalnya dimana kemungkinan bagi setiap atlet di dojang akan bertemu dengan dojang lain yang berada di dalam satu wilayah yang sama sangat besar. Hal ini mendorong pelatih memiliki strategi yang berbeda-beda dan tidak di standarkan di organisasi taekwondo profesional agar setiap pelatih dan atlet memiliki keunggulan masingmasing. Sehingga, meskipun peran organisasi sangat besar bagi kemajuan prestasi atlet karena berperan sebagai induk yang menaungi atlet dan pelatih, peran pelatih dalam pembinaan atlet lebih penting untuk didalami karena pelatih adalah pihak yang paling mengetahui mengenai pembinaan atlet di dalam dojang yang diampunya serta menjadi pihak yang dapat merealisasikan visi dan misi organisasi dalam pelaksanaan pembinaan sehari-hari.

Pelatih utama yang tergabung di organisasi taekwondo profesional ratarata memiliki pengalaman melatih lebih dari 10 tahun. Pelatih utama juga setidaknya telah memegang DAN 4 Internasional (Kukkiwon) dan pernah membimbing atlet hingga kejuaraan nasional dan internasional serta mendapatkan medali. Pelatih juga dibantu oleh asisten pelatih yang rata-rata telah memegang DAN 1, 2, dan 3 Internasional (Kukkiwon) serta dipersiapkan menjadi suksesi pengganti pelatih tersebut di masa depan. Dengan pengalaman melatih yang cukup lama tersebut, pelatih memiliki pengalaman yang cukup dalam dan dapat digali bagaimana ia sukses membimbing atletnya hingga bisa mendapatkan juara nasional dan internasional mengingat pelatih rata-rata membimbing atlet dimulai sejak atlet tersebut memegang sabuk putih hingga saat ini sukses menjadi atlet berprestasi. Pelatih dalam melatih juga harus memiliki kompetensi sehingga ia bisa bertahan (survive) dalam melatih sehingga ia bisa membimbing atletnya dengan baik. Posisi pelatih yang dianggap sangat penting bagi pelaksanaan pengembangan atlet membuat peneliti ingin melihat lebih dalam mengenai peran pelatih dalam membangun prestasi atlet. Sehingga, tujuan dari penelitian ini adalah untuk mengetahui peran pelatih dalam pembinaan prestasi atlet taekwondo di dojang utama yang tergabung dalam organisasi taekwondo profesional.

\section{METODE}

\section{Desain Penelitian}

Penelitian ini menggunakan pendekatan kualitatif. Penelitian kualitatif dipilih karena penelitian ini berorientasi untuk mengeksplor lebih dalam masalah atau isu (Creswell, 2007). Pendekatan penelitian kualitatif yang digunakan dalam penelitian ini adalah fenomenologi untuk mendapatkan esensi dari pengalaman pelatih dalam membangun prestasi atlet. 


\section{Lokasi Penelitian}

Penelitian dilakukan pada pelatih utama di dojang yang tergabung di dalam organisasi taekwondo profesional Daerah Istimewa Yogyakarta.

\section{Responden Penelitian}

Sumber data utama dalam penelitian ini adalah data yang berasal dari responden penelitian. Sumber data lain dalam penelitian ini adalah informan (orangtua dan atlet), observasi, dan data dokumen. Responden dalam penelitian ini adalah empat pelatih utama di dojang yang berada di organisasi taekwondo profesional. Kriteria responden adalah pelatih tergabung dalam organisasi taekwondo profesional DIY dan menjadi pelatih utama dalam dojang dengan pengalaman melatih lebih dari 10 tahun, memegang DAN Internasional (Kukkiwon) minimal DAN 4, merupakan pelatih dengan sertifikasi nasional, dan pernah membimbing atlet yang mengikuti kejuaraan nasional serta mendapatkan medali

\section{Teknik Pengumpulan Data}

Pengumpulan data dilakukan melalui pendekatan interpersonal dengan meminta kesediaan calon responden untuk berpartisipasi di dalam penelitian, menjelaskan proses penelitian yang akan dijalani, dan menyusun jadwal dengan calon responden yang bersedia. Data terkait dengan penelitian ini di ambil dengan tiga cara yaitu observasi, wawancara mendalam (in-depth interview), dan studi dokumen untuk memperoleh kedalaman data dan berfungsi sebagai metode triangulasi (Moleong, 2013).

\section{Keabsahan Data Penelitian}

Penelitian ini menggunakan teknik triangulasi metode dan triangulasi sumber. Triangulasi metode dilakukan dengan cara mengkonfirmasi data hasil wawancara dengan responden utama kepada dua informan yaitu orangtua atlet dan atlet. Triangulasi sumber dilakukan dengan cara membandingkan hasil wawancara dengan observasi, curriculum vitae pelatih, materi atau kurikulum pelatihan, sertifikat pelatih, dan sertifikat kejuaraan atlet. Proses verifikasi selanjutnya adalah melakukan pengecekan data yang dilakukan dengan cara meminta responden untuk memeriksa dengan seksama (member checking) dan mencermati keakuratan hasil penelitian dengan seksama (Creswell, 2007). Peneliti juga melaksanakan proses confidentiality, transferability, dependability, dan confirmability.

\section{Prosedur Penelitian}

Sebelum dilaksanakan proses penelitian, peneliti meminta persetujuan tertulis dari responden (informed consent). Setelah responden menyatakan persetujuannya dalam informed consent, peneliti kemudian memulai proses pelaksanaan penelitian. Peneliti melaksanakan proses wawancara, observasi, dan studi dokumen dengan menyesuaikan jadwal responden dengan terlebih dahulu membuat janji. Proses yang dilakukan oleh peneliti setelah pengambilan data adalah membuat verbatim dan koding berdasarkan hasil wawancara, serta mengumpulkan hasil observasi dan studi dokumen. Setelah itu, peneliti mengkonfirmasi hasil temuan kepada responden agar hasil temuan tersebut benar-benar sesuai dengan maksud yang dikatakan oleh responden. 


\section{Prosedur Analisis dan Interpretasi Data}

Analisis data pada penelitian ini adalah dengan memproses transkrip verbatim yang diperoleh dengan proses epoche (bracketing), phenomenological reduction, imaginative variation, serta synthesis of meaning and essences (Moustakas, 1994). Analisis data ini dipilih karena dianggap sebagai salah satu proses analisis data yang mampu memilah esensi dari fenomena yang diteliti (Moustakas, 1994).

Tabel 1. Profil responden penelitian

\begin{tabular}{lllll}
\hline Responden & \multicolumn{1}{c}{$\mathbf{1}$} & \multicolumn{1}{c}{$\mathbf{2}$} & \multicolumn{1}{c}{$\mathbf{3}$} & \multicolumn{1}{c}{$\mathbf{4}$} \\
\hline Gelar & Sabeum Nim & Sabeum Nim & Sabeum Nim & Sabeum Nim \\
Jenis Kelamin & Laki-laki & Laki-laki & Laki-laki & Laki-laki \\
Usia & 48 tahun & 61 tahun & 37 tahun & 43 tahun \\
DAN & 4 Kukkiwon & 5 Kukkiwon & 4 Kukkiwon & 5 Kukkiwon \\
Dojang & BTC & BP & BETA & SM \\
Lama Melatih & 28 tahun & 34 tahun & 16 tahun & 21 tahun \\
\hline
\end{tabular}

Peneliti kemudian membangun rapport kepada keempat responden, atlet, dan orangtua atlet, kemudian melakukan proses wawancara, observasi, dan

Tabel 2. Proses pengambilan data

\begin{tabular}{|c|c|c|}
\hline Metode & Subjek & Tanggal \\
\hline \multirow[t]{2}{*}{ Wawancara } & Responden 1, 2, 3, 4 & $\begin{array}{l}2 \text { Agustus } 2016 \text { - } 21 \text { September } \\
2016\end{array}$ \\
\hline & $\begin{array}{l}\text { Atlet dan orangtua atlet } \\
\text { masing-masing responden }\end{array}$ & 3 September 2016 - 9 Oktober 2016 \\
\hline \multirow[t]{4}{*}{ Observasi } & Responden 1 & 1 Agustus 2016 - 9 September 2016 \\
\hline & Responden 2 & 5 Agustus 2016 - 3 September 2016 \\
\hline & Responden 3 & $\begin{array}{l}7 \text { Agustus } 2016 \text { - } 21 \text { September } \\
2016\end{array}$ \\
\hline & Responden 4 & $\begin{array}{l}13 \text { Agustus } 2016 \text { - } 3 \text { September } \\
2016\end{array}$ \\
\hline \multirow{8}{*}{$\begin{array}{l}\text { Data } \\
\text { Dokumen }\end{array}$} & Responden 1 & 30 November 2016 \\
\hline & Atlet Responden 1 & 29 November 2016 \\
\hline & Responden 2 & 4 Desember 2016 \\
\hline & Atlet Responden 2 & 4 Desember 2016 \\
\hline & Responden 3 & 29 November 2016 \\
\hline & Atlet Responden 3 & 29 November 2016 \\
\hline & Responden 4 & 1 Desember 2016 \\
\hline & Atlet Responden 4 & 28 November 2016 \\
\hline
\end{tabular}

pengambilan data dokumen yang terlampir pada tabel 2 berikut.

\section{HASIL DAN PEMBAHASAN}

Pelaksanaan Penelitian

Penelitian diawali dengan mencari informasi tentang calon responden yang sesuai dengan kriteria responden penelitian yang telah ditetapkan sebelumnya. Penelitian ini melibatkan 4 orang responden yang terlampir dalam tabel 1 berikut. 


\section{Hasil Penelitian}

Berdasarkan pengalaman responden dalam melatih diketahui bahwa ada tiga strategi pembinaan yang mempengaruhi kesuksesan seorang pelatih dalam melatih hingga atlet mampu mencapai prestasi yaitu juara nasional. Tiga strategi tersebut adalah membangun dukungan, pembelajaran, dan kepelatihan. Membangun dukungan yang dimaksud adalah membina hubungan yang baik dengan atlet, orangtua atlet, dan organisasi induk. Membangun dukungan dilandasi oleh komunikasi yang baik antara pelatih, orangtua, dan atlet, persaudaraan yang terjalin, serta dukungan yang diberikan oleh organisasi. Pembelajaran yang dimaksud adalah proses yang dilakukan oleh pelatih untuk mendapatkan ilmu baik dari diri sendiri, orang lain, maupun sumber-sumber belajar lainnya. Pembelajaran dilandasi oleh dua hal yaitu pengalaman dan pengembangan diri. Kepelatihan yang dimaksud adalah faktor-faktor dari dalam diri pelatih yang terwujud di dalam perilaku yang dilakukan oleh pelatih kepada atlet dalam pembinaan prestasi. Kepelatihan terdiri atas pembinaan mental, langkah mencapai prestasi, dan kepekaan terhadap atlet. Berikut merupakan dinamika strategi pembinaan prestasi atlet oleh pelatih:

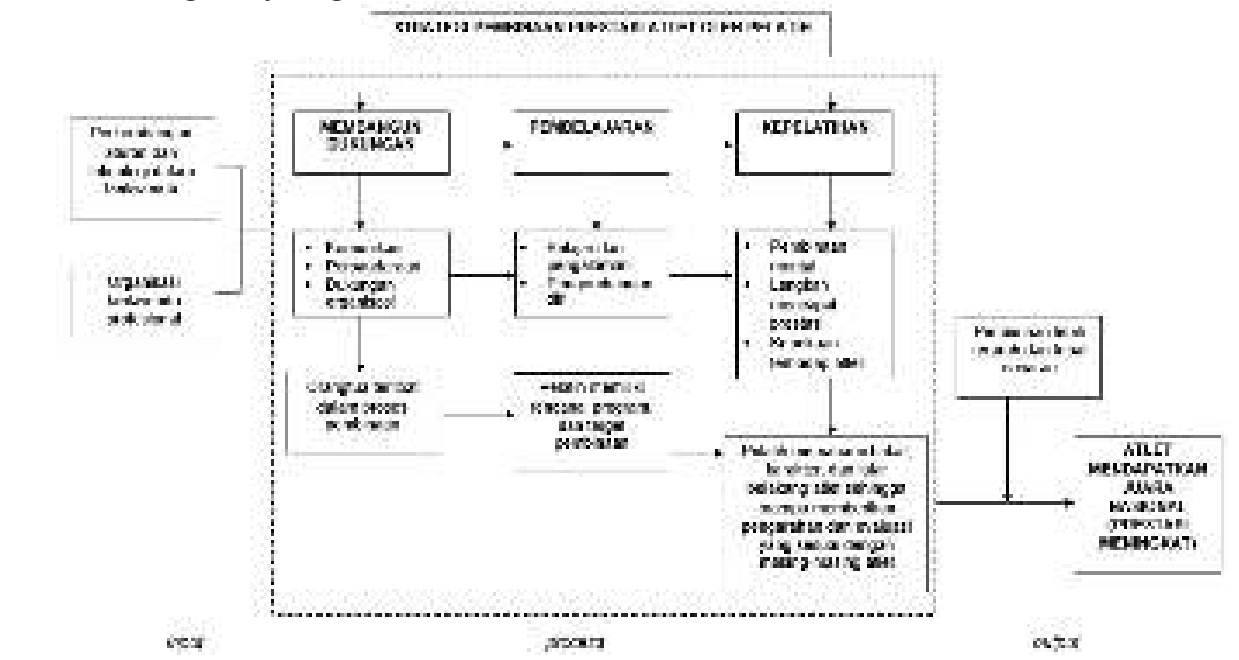

Bagan 1. Dinamika Strategi Pembinaan Prestasi Atlet oleh Pelatih

Dinamika strategi pembinaan prestasi atlet taekwondo oleh pelatih tersebut dapat disimpulkan bahwa strategi tersebut dipengaruhi oleh faktorfaktor yang berada di luar pelatih yaitu perkembangan aturan dan teknologi dalam taekwondo dan organisasi taekwondo profesional sebagai induk yang menaungi pelatih dan atlet. Faktor diluar pelatih tersebut mempengaruhi strategi pembinaan yang dilakukan oleh pelatih agar mampu meningkatkan prestasi atlet, yaitu dengan membangun dukungan, pembelajaran, dan kepelatihan. Ketiga hal ini secara bersama-sama berperan di dalam meningkatkan prestasi atlet yang dibina oleh pelatih.

\section{Pembahasan}

Bompa (1994) menyatakan bahwa ada faktor-faktor yang mempengaruhi kualitas pelatihan dan secara langsung berpengaruh $t$ erhadap performansi atlet yang dijelaskan melalui bagan 2 berikut: 


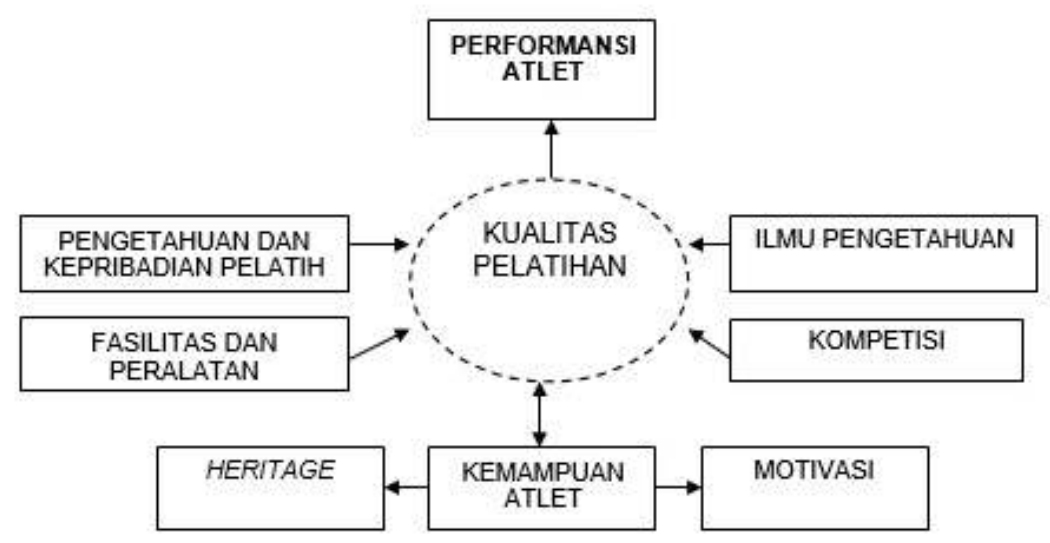

\section{Bagan 2. Faktor yang Mempengaruhi Kualitas Pelatihan}

Kualitas pelatihan ditentukan berdasarkan berbagai faktor, yaitu ilmu pengetahuan, kompetisi, fasilitas dan peralatan, pengetahuan dan kepribadian pelatih, serta kemampuan atlet yang dipengaruhi oleh motivasi dan heritage. Pengetahuan dan kepribadian pelatih tampak dari hasil penelitian yang merupakan strategi ketiga yaitu kepelatihan. Ilmu pengetahuan yang diterapkan kepada atlet tampak dari hasil penelitian yang merupakan strategi kedua yaitu pembelajaran. Hal ini juga terkait pemberian motivasi kepada atlet dan pengenalan pelatih terhadap kemampuan dan heritage atlet. Kompetisi merupakan ranah dari dukungan organisasi yang merupakan subtema dari strategi pembinaan pertama yaitu membangun dukungan. Keseluruhan faktor yang mempengaruhi kualitas pelatihan tidak terlepas dari dukungan pihak-pihak terdekat atlet yaitu orangtua dan komunikasi yang baik antara pelatih, orangtua, dan atlet. Faktor-faktor ini secara bersama-sama mempengaruhi kualitas pelatihan yang berdampak secara langsung terhadap performansi atlet untuk mendapatkan juara. Hal lain yang berpengaruh terhadap pelatihan adalah sistem di dalam pelatihan tersebut seperti ditunjukkan pada bagan 3 (Bompa, 1994):

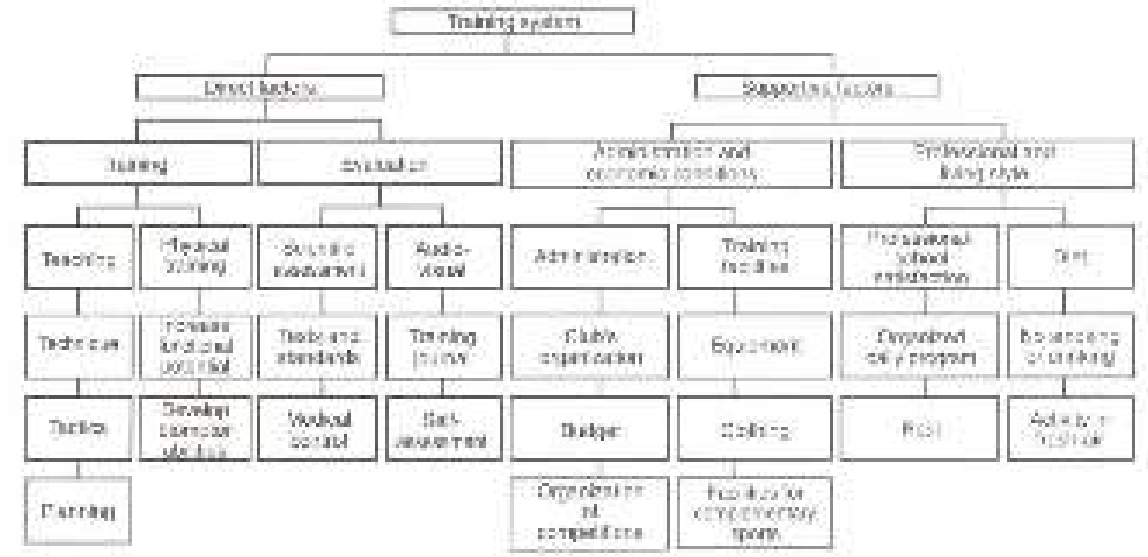

Bagan 3. Sistem Pelatihan 
Bagan 3 diatas memperlihatkan faktor-faktor yang berpengaruh terhadap sistem pelatihan. Faktor tersebut adalah faktor langsung yang terdiri atas pelatihan dan evaluasi, serta faktor pendukung yang terdiri atas kondisi administrasi dan ekonomi serta gaya hidup dan profesional dari atlet. Faktor langsung dalam pelatihan yaitu pengajaran pelatih, teknik, taktik, rencana pelatihan, pelatihan fisik, meningkatkan fungsi potensial, dan mengembangkan kemampuan biomotorik serta faktor langsung terkait evaluasi dilakukan oleh pelatih kepada atlet. Faktor-faktor tersebut terlampir dalam kurikulum pembinaan yang disusun oleh pelatih.

\section{Kesimpulan}

Penelitian ini menghasilkan temuan yaitu strategi pembinaan prestasi yang dilakukan oleh pelatih untuk membentuk atlet berprestasi. Strategi tersebut dipengaruhi oleh faktor-faktor yang berada di luar pelatih (input) yaitu perkembangan aturan dan teknologi dalam taekwondo dan organisasi taekwondo profesional sebagai induk yang menaungi pelatih dan atlet. Faktor diluar pelatih tersebut mempengaruhi strategi pembinaan yang dilakukan oleh pelatih agar mampu meningkatkan prestasi atlet (process), yaitu dengan (1) membangun dukungan, (2) pembelajaran, dan (3) kepelatihan. Strategi tersebut diwujudkan dalam bentuk komunikasi, persaudaraan dengan orangtua atlet, dan dukungan organisasi; belajar dari pengalaman dan pengembangan diri agar senantiasa dapat memberikan materi yang sesuai dengan perkembangan zaman; serta melaksanakan pembinaan mental, menetapkan langkah mencapai prestasi, dan kepekaan terhadap atlet.
Strategi yang terwujud dalam bentuk perilaku tersebut menyebabkan pelatih dapat memberikan pengarahan pada masing-masing atlet secara tepat dan terarah sehingga memberikan kontribusi terhadap kesuksesan pelatih untuk meningkatkan prestasi atlet yang dibina (output).

\section{Saran}

Bagi Organisasi Taekwondo Profesional

Organisasi taekwondo profesional diharapkan dapat memberikan penyegaran kepada pelatih mengenai peran pelatih dalam pembinaan prestasi serta mempersiapkan generasi selanjutnya atau asisten pelatih untuk menjadi pelatih yang sukses. Untuk memberikan penyegaran, organisasi taekwondo profesional menyisipkan materi strategi pembinaan prestasi yang dipresentasikan dalam forum seperti seminar. Organisasi taekwondo profesional juga membuat program untuk pelatih utama memberikan materi ini kepada asisten pelatih. Dalam melatih, pelatih dibantu oleh asisten pelatih yang telah memegang sabuk hitam dengan kualifikasi DAN 1, 2, atau 3 Internasional (Kukkiwon). Asisten pelatih ini adalah yang kelak akan menggantikan peran pelatih dalam membina atlet berprestasi. Oleh karena itu, penting bagi organisasi taekwondo profesional untuk meneruskan strategi pembinaan atlet yang dilakukan oleh pelatih yang sukses dalam membina prestasi atlet sehingga asisten pelatih dapat mempelajarinya dan menerapkannya ketika mereka sudah menjadi pelatih utama. Sehingga, proses mentoring untuk asisten pelatih dirasa perlu untuk dilakukan sebagai cara transfer strategi pembinaan prestasi atlet oleh pelatih. Proses mentoring ini dilakukan dalam waktu 5 bulan dengan 
target yang diberikan kepada asisten pelatih setiap bulannya. Pelatih utama sebagai mentor memberikan kegiatankegiatan seperti gathering, materi pengembangan atlet, menceritakan pengalamannya ketika melatih, dan memberikan feedback kepada asisten pelatih dalam pelaksanaannya. Pelaksanaan kegiatan-kegiatan tersebut secara lebih jelas dijabarkan lebih lanjut di dalam lampiran intervensi.

\section{Bagi Peneliti Selanjutnya}

Penelitian ini memiliki beberapa keterbatasan antara lain terbatasnya jumlah pelatih yang menjadi responden dan responden utama yang menjadi subjek dari penelitian ini belum mencakup kepada atlet dan orangtua. Oleh karena itu peneliti selanjutnya dapat mengembangkan penelitian ini dengan melihat strategi yang diterapkan oleh atlet agar dapat berprestasi dan peran orangtua seperti pola asuh dan dukungan yang diberikan sehingga mereka memiliki anak yang berprofesi sebagai atlet sukses. Penelitian lanjutan juga diharapkan dapat memperhatikan pemilihan responden pelatih dalam bidang olahraga lainnya.

\section{Kepustakaan}

Barton, J., Griffin, M., \& Pretty, J. (2012). Exercise-, nature- and socially interactive-based initiatives improve mood and self-esteem in the clinical population. Journal of Perspectives in Public Health, 132 (2), 89-96.

doi: $10.1177 / 1757913910393862$

Bompa, T. O. (1994). Theory and Methodology of Training: The Key to Athletic Performance (3 ${ }^{\text {rd }}$ ed.). Iowa: Kendall/Hunt Publishing Company.
Bompa, T. O. (2000). Total Training for Young Champions. Champaign: Human Kinetics.

Bradley, J., Keane, F., \& Crawford, S. (2013). School sport and academic achievement. Journal of School Health, 83 (1), 8-13. doi: 10.1111/j.1746-1561.2012.00741.x

Cashmore, E. (2008). Sport and Exercise Psychology: The Key Concepts $\left(^{\text {nd }}\right.$ ed.). New York: Routledge.

Chrila, D., \& Chrila, M. (2015). The grille method for professional evaluation of sport coach. Lucrări Stiințifice, 18 (2), 55-62. Retrieved from http://lsma.ro/index.php/lsma/articl e/viewFile/874/pdf

Chuan, C., Yusof, A., \& Shah, P. M. (2013). Sports involvement and academic achievement: A study of Malaysian university athletes. International Education Studies, 6 (2), 12-21. doi: 10.5539/ies.v6n2p12

Creswell, J.W. (2007). Qualitative Inquiry and Research Design: Choosing Among Five Approaches ( $2^{\text {nd }}$ ed.). Thousand Oaks: Sage Publications, Inc.

Departemen Pendidikan Nasional. (2008). Kamus Besar Bahasa Indonesia. Jakarta: PT. Gramedia Pustaka Utama.

Domazet, S. L., Tarp, J., Huang, T., Gejl, A. K., Andersen, L. B, Froberg, K., \& Bugge, A. (2016). Associations of physical activity, sports participation and active commuting on mathematic performance and inhibitory control in adolescents. PLOS ONE, 11 (1), 12-23. doi: 10.1371/journal.pone.0146319

Dosil, J. (2008). The Sport Psychologist's Handbook: A Guide for Sport-Specific Performance Enhancement. New York: John Wiley \& Sons. 
Enre, A. (1979). Sumbangan Psikologi Bagi Dunia Olahraga. Yogyakarta: Yayasan Pembina Fakultas Psikologi UGM.

Gwozdecky, G. (2006, Januari). A deeper bench is a better bench. USA Hockey Magazine. Retrieved from http://www.usahockeymagazine.co $\mathrm{m} /$ article/a- deeper-bench-is

Harrell, D. J. (2013). The impact of taekwondo training on the creative abilities and personality/character traits of students: A quantitative and qualitative analysis. Taekwondo Journal of Kukkiwon, 4 (3), 83-99.

Howland, J. (2006). Mental skills training for coaches to help athletes focus their attention, manage arousal, and improve performance in sport. The Journal of Education Sport Psychology Issue, 187 (1), 49-66.

Jarvis, M. (1999). Sport Psychology. London: Routledge Modular Psychology.

Jonker, L., Elferink-Gemser, M.T., \& Visscher, C. (2010). Differences in self-regulatory skills among talented athletes: the significance of competitive level and type of sport. Journal of Sports Sciences, 28, 901-908. doi: 10.1080/02640411003797157.

Jowett, S. \& Poczwardowski, A. (2007). Understanding the coach-athlete relationship. Social Psychology in Sport, 3-14, doi: 10.1080/21520704.2015.1054537

MacDonald, D. J., Côté, J., \& Deakin, J. (2010). The impact of informal coach training on the personal development of youth sport athletes. International Journal of Sports Science E Coaching, 5 (3), 363372. doi: 10.1260/1747-9541.5.3.363

Matveyev, L. (1981). Fundamentals of Sports Training. (A. P. Zdornykh,
Trans.). Podolsk: Progress Publishers.

Moleong, L. J. (2013). Metodologi Penelitian Kualitatif: Edisi Revisi. Bandung: PT. Remaja Rosdakarya.

Moran, M. (2004). The effects of mixed martial arts on behavior of male children with attention deficit hyperactivity disorder. Dissertation. Hofstra University, Hampstead, N.Y.

Moustakas, C. (1994). Phenomenological Research Methods. New York: Sage Publications, Inc.

Naylor, A. (2006). The coach's dilemma: balancing playing to win and player development.The Journal of Education Sport Psychology Issue, 187 (1), 31-48.

North, J. (2007). Increasing participation in sport: The role of the coach. The National Coaching Foundation.

Pottle, B., \& Pottle, K. (2013). Taekwondo: A Practical Guide to The World's Most Popular Martial Art.

Reade, I., Rodgers, W., \& Spriggs, K. (2008). New ideas for high performance coaches: A case study of knowledge transfer in sport science. International Journal of Sports Science \& Coaching, 3 (3), 335-354.

Republik Indonesia, Undang-Undang tentang Sistem Keolahragaan Nasional, UU No. 3 Tahun 2005, LN No. 89 Tahun 2005, TLN No. 4535

Sajoto, M. (1990). Peningkatan dan Pembinaan: Kekuatan dan Kondisi Fisik dalam Olahraga. Semarang: IKIP Semarang Press.

Setyobroto, S. (2002). Psikologi Olahraga. Jakarta: Universitas Negeri Jakarta.

Sukys, S., Lisinskiene, A., \& Tilindiene, I. (2015). Adolescents' participation in sport activities and attachment to parents and peers. Social Behavior 
And Personality, 43 (9), 1507-1518.

doi: 10.2224/sbp.2015.43.9.1507

Suryadi, V. Y. (2003). Taekwondo: Poomsae

Taegeuk. Jakarta: PT. Gramedia Pustaka Utama

Taekwondo Indonesia (2013). Sejarah Singkat Taekwondo Indonesia. Retrieved from http://www.taekwondoindonesia.com/profil-PBTI.php

Vella, S. A., Oades, L. G., \& Crowe, T. P. (2013). A pilot test of transformational leadership training for sports coaches: Impact on the developmental experiences of adolescent athletes. International Journal of Sports Science \& Coaching, 8 (3), 513-530. doi: 10.1260/17479541.8.3.513 